\title{
PHÁT TRIỂN KỸ NĂNG MỀM CHO SINH VIÊN TRƯờNG ĐẠI HỌC THỦ DẦU MỘT ĐẠT CHUẨN ĐẦU RA THEO CDIO
}

\author{
Phạm Kim Cương \\ Thạc sĩ. Trường Đại học Thủ Dầu Một. Email: cuongpk@tdmu.edu.vn
}

DOI: $\underline{10.37550 / \mathrm{tdmu} . \mathrm{CFR} / 2021.01 .120}$

\section{Tóm tắt}

Quá trình đổi mới toàn diện và hội nhập kinh tế quốc tế hiện nay ở Việt Nam được đánh giá là một xu thế tất yếu, mở ra nhiều co hội cũng nhu thách thức cho các ngành kinh tế, các doanh nghiệp và người lao động. Nhằm nâng cao chất lượng nguồn nhân lực, thích úng và đáp úng nhu cầu của các doanh nghiệp và người sủ dụng lao động, đòi hỏi các co. sở đào tạo phải không ngùng đổi mới, cải tiến chương trình đào tạo, phương pháp tiếp cận và giảng dạy. Qua đó thu hẹp khoảng cách giũa chất lượng đào tạo và nhu cầu của các doanh nghiệp. Song song với đó, về phía người học cần nhận thức được tầm quan trọng của việc chủ động lĩnh hội tri thức, bổ sung và rèn luyện kỹ năng, để sau quá trình đào tạo sã̃n sàng và đáp ứng được các tiêu chuẩn về năng lực làm việc của doanh nghiệp. Bài viết tập trung vào thưc trạng kỹ năng mềm của sinh viên truò̀ng Đại hoc Thủ Dầu Một và đề xuất một số biện pháp phát triển kỹ năng mềm đạt chuẩn đầu ra theo CDIO.

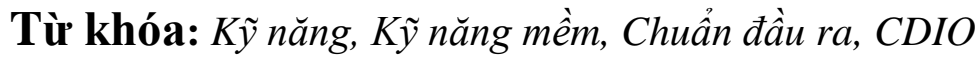

\section{1. Đặt vấn đề}

Nghị quyết số 05 năm 2018 của Hội đồng trường Đại học Thủ Dầu Một đã xác định giá trị cốt lõi của nhà trường là: Khát vọng - Trách nhiệm - Sáng tạo; Xây dựng đội ngũ cán bộ, giảng viên, sinh viên có ý thức phấn đấu vươn lên đỉnh cao trí thức, ước vọng tới những điều tốt đẹp và quyết tâm thực hiện một cách mạnh mẽ nhất; Có thái độ tích cực và tinh thần trách nhiệm với chính mình, với gia đình, xã hội, Tổ quốc, nhân loại; Có đủ năng lực và kỹ năng để chịu trách nhiệm; Có tư duy đổi mới, có đủ năng lực và trình độ chuyên môn để tạo ra giá trị mới đáp ứng yêu cầu và phục vụ cho sự phát triển của xã hội.

Nghị quyết cũng xác định triết lý giáo dục của nhà trường: Học tập trải nghiệm nghiên cứu khoa học ứng dụng và phục vụ cộng đồng. Sinh viên trở thành người phát triển toàn diện về năng lực và tố chất thông qua quá trình học tập trải nghiệm, kết hợp với nghiên cứu khoa học nhằm phục vụ cộng đồng. Để hiện thực hóa triết lý giáo dục, trong những năm qua trường Đại học Thủ Dầu Một không ngừng cải tiến, đổi mới phương pháp giảng dạy và cải tiến chương trình đào tạo theo hướng đáp ứng yêu cầu và nhu cầu của xã hội, 
trong đó chú trọng việc xây dựng và phát triển chương trình đào tạo theo chuẩn CDIO. Những thay đổi bước đầu đã góp phần thay đổi cả về chất và lượng về sản phẩm đào tạo của nhà trường, vị thế và uy tín của trường Đại học Thủ Dầu Một ngày càng được khẳng định và nâng cao.

Tiếp nối những kết quả đạt được, bên cạnh quá trình cải tiến và hoàn thiện chương trình đào tạo chuyên môn, cũng cần chú trọng đến việc trang bị và rèn luyện cho sinh viên những nhóm kỹ năng mềm đạt chuẩn đầu ra theo $\mathrm{CDIO}$, để sinh viên không chỉ tự tin, thích nghi với môi trường học tập đại học mà còn đáp ứng được những tiêu chuẩn khắt khe của nhà tuyển dụng về kỹ năng làm việc, kỹ năng chung sống và khẳng định giá trị của bản thân.

\section{Nội dung}

\subsection{Khái niệm, đặc điểm và phân loại kỹ năng mềm}

\subsubsection{Khái niệm}

Kỹ năng là khả năng thực hiện có kết quả một hành động nào đó bằng cách vận dụng những tri thức, những kinh nghiệm đã có phù hợp với điều kiện cho phép. Kỹ năng không chỉ đơn thuần về mặt kỹ thuật của hành động mà còn là biểu hiện năng lực của con người. Ngân hàng Thế giới gọi thế kỷ 21 là kỷ nguyên của kinh tế dựa vào kỹ năng (Skills Based Economy). Còn đối với các nhà tuyển dụng và người sử dụng lao động thường chú trọng đến năng lực của người được tuyển dụng. Thang năng lực dựa vào phạm trù nhận thức đã được Giáo sư Benjamin Bloom, một nhà khoa học giáo dục người Mỹ phát triển và công bố năm 1956, năng lực này bao gồm 3 nhóm tiêu chí: kiến thức, kỹ năng và thái độ. Trong lĩnh vực giáo dục, có thể gọi nhóm kiến thức chính là kỹ năng cứng, là những kiến thức, hiểu biết hoặc trải nghiệm thực hành có tính chất thiên về kỹ thuật. Kỹ năng cứng thường mang tính chuyên môn. Nói cách khác, kỹ năng cứng dùng để chỉ trình độ, kiến thức chuyên môn, bằng cấp và chứng chỉ chuyên môn. Loại kỹ năng này đa phần được đào tạo ở các trường học. Thông qua các môn học chính, kỹ năng cứng sẽ dần được hình thành.

Kỹ năng mềm (soft skill) là những kỹ năng quan trọng liên quan tới mặt trí tuệ cảm xúc. Kỹ năng mềm chứng tỏ khả năng hòa nhập, tương tác với xã hội, cộng đồng, tập thể,... Có thể thấy, kỹ năng mềm không mang tính chuyên môn mà liên quan tới tính cách, cảm xúc nhiều hơn. Khác với kỹ năng cứng thường được hình thành và tích lũy từ trường học, "Trường đời và xã hội” thường được ví là nơi "tôi luyện” kỹ năng mềm. Tuy nhiên trong giai đoạn tác động mạnh mẽ của cuộc cách mạng 4.0 ảnh hưởng rất nhanh và mạnh mẽ đến thái độ và lối sống của sinh viên, để các kỹ năng mềm sinh viên tiếp cận đúng với yêu cầu việc làm và nhu cầu của nhà tuyển dụng, cũng như thúc đẩy nhanh quá trình hình thành và phát triển các kỹ năng mềm trong sinh viên, Trường Đại học Thủ Dầu Một đã chú trọng đến việc bồi dưỡng các kỹ năng, đồng thời hình thành nhiều sân chơi, câu lạc bộ, đội nhóm... để sinh viên tham gia trải nghiệm, tích lũy kỹ năng.

Như vậy, kỹ năng mềm (hay còn gọi là Kỹ năng thực hành xã hội) là thuật ngữ liên quan đến trí tuệ xúc cảm, thuộc về tính cách con người dùng để chỉ các kỹ năng quan trọng 
trong cuộc sống con người như: kỹ năng sống, giao tiếp, lãnh đạo, làm việc theo nhóm, kỹ năng quản lý thời gian, thư giãn, vượt qua khủng hoảng, sáng tạo và đổi mới...

\subsection{2 Đặc điểm}

- Kỹ năng mềm không phải là yếu tố thuộc về bẩm sinh: kỹ năng mềm là khả năng thiên về mặt tinh thần của cá nhân nhằm đảm bảo cho quá trình thích ứng với người khác, công việc nhằm duy trì tốt mối quan hệ tích cực và góp phần hỗ trợ thực hiện công việc một cách hiệu quả. Do vậy kỹ năng mềm hình thành theo sự trải nghiệm, áp dụng kiến thức vào giải quyết tình huống từ đó rút ra những bài học kinh nghiệm, và do đó nó không phải là yếu tố bẩm sinh. Để có được kỹ năng mềm tốt, điều đầu tiên và quan trọng nhất là cần hình thành được ở người học một thái độ tích cực và nhận thức đúng đắn về tầm quan trọng của kỹ năng mềm. Để từ đó họ sẵn sàng, chủ động cho một tâm thế thấu hiểu và tích lũy và lâu dài hơn nữa là quá trình tự tập luyện bằng nhiều hình thức, phương pháp với sự nỗ lực không ngừng.

- Kỹ năng mềm không chỉ là biểu hiện của trí tuệ cảm xúc: mà nó còn thể hiện sức mạnh của việc thiết lập và duy trì mối quan hệ xã hội. Kỹ năng mềm giúp cá nhân thích ứng nhanh với từng hoàn cảnh khác nhau như khi làm việc nhóm, xử lý tình huống bất ngờ, xử lý dữ liệu công việc, hay thậm chí là những thay đổi ngoại cảnh, thay đổi môi trường sống và làm việc,... Trong mỗi môi trường sống, mỗi môi trường làm việc khác nhau thì có những yêu cầu khác nhau. Người có kỹ năng mềm linh hoạt sẽ làm chủ được tình huống, biết tìm ra cách để giải quyết vấn đề hợp lý, hiệu quả, khéo léo khi ứng xử với mọi người,...

- Kỹ năng mềm đuợc hình thành bằng con đuờng trải nghiệm: các kỹ năng mềm không dễ để có được vì nó được hình thành từ những trải nghiệm thực tế, trong mối quan hệ giữa con người và hoàn cảnh xác định nên. Kiến thức chuyên môn sẽ được được tích lũy dưới các dạng lý thuyết hoặc thực hành, qua quá trình lĩnh hội và đánh giá sẽ tạo thành khối kiến thức và kỹ năng cứng. Trong khi kỹ năng mềm không hoàn toàn hình thành bằng cách truyền đạt thông tin lý thuyết, mà đòi hỏi khả năng thích ứng của người học đối với môi trường thực tế, những đặc thù của môi trường thực tế này lại luôn vận động và biến đổi không ngừng. Do đó kỹ năng mềm chỉ thật sự tồn tại và phát huy hiệu quả khi người học làm chủ được bản thân và ứng biến linh hoạt trong thực tế bằng sự trải nghiệm.

- Kỹ năng mềm góp phần hỗ trợ cho kiến thức và kỹ năng chuyên môn, mà đặc biệt là "kỹ năng cứng": kỹ năng cứng là những kỹ năng cơ bản trong nghề nghiệp, thuộc về chuyên môn, nghiệp vụ, được thể hiện thông qua bảng lý lịch, trình độ học vấn hay cụ thể là qua các văn bằng, chứng chỉ. Ngược với nó thì kỹ năng mềm là những kinh nghiệm, sự thành thạo chuyên môn, tính linh hoạt trong xử lý tình huống thực tế. Hiện nay trong phỏng vấn, tuyển dụng và đánh giá nhân sự nhà tuyển dụng không chỉ quan tâm về trình độ học vấn mà kỹ năng mềm cũng như kinh nghiệm công việc cũng là những yếu tố rất quan trọng được chú ý, quan tâm. Thậm chí nhiều kết quả nghiên cứu của các nhà khoa học trên thế giới gần đây chỉ ra rằng: để thành đạt trong công việc và cuộc sống thì kỹ năng mềm (trí tuệ cảm xúc) chiếm $85 \%$, kỹ năng cứng (trí tuệ logic) chỉ chiếm $15 \%$. Chính vì vậy kỹ năng mềm sẽ là "đòn bẩy" phát triển tư duy và kỹ năng cứng lên một cách hiệu quả. Chìa khóa đi đến thành công nhanh nhất đó là trau dồi và bồi dưỡng 2 nhóm kỹ năng này nhuần nhuyễn, hiệu quả. 
- Kỹ năng mềm không "cố định" cho tất cả các ngành nghề: với mỗi ngành nghề cần đến những nhóm kỹ năng khác nhau nhất định. Chẳng hạn với vị trí nhân viên phòng Kinh doanh thì kỹ năng giao tiếp, thuyết phục khách hàng lại chính là kỹ năng "cứng", hay chính là chuyên môn của nghề nghiệp. Đối với ngành Hướng dẫn viên du lịch, kỹ năng thuyết minh, thuyết trình và kỹ năng giao tiếp được coi là kỹ năng cứng. Nhưng với vị trí Lập trình viên máy tính thì đương nhiên đó là những kỹ năng "mềm". Việc xác định rõ "mềm", "cứng" và nhận ra điểm mạnh, điểm yếu, những mặt thiếu hụt của bản thân là yêu cầu đầu tiên và rất quan trọng để trau dồi kỹ năng "mềm”. Kỹ năng nghề là căn bản, đặc trưng chuyên môn, nghiệp vụ còn kỹ năng mềm mang tính bổ trợ cho kỹ năng cứng, nghiệp vụ chuyên môn. Bên cạnh đó có những kỹ năng mềm mang tính xã hội, quan hệ giữa con người với con người. Những kỹ năng như giao tiếp, lắng nghe, kỹ năng thuyết trình,... giúp con người dễ dàng thích ứng, hòa nhập với mọi người, linh hoạt vận dụng, triển khai công việc. Nên giữa các nghề nghiệp sẽ có sự giao thoa của những kỹ năng mềm.

\subsubsection{Phân loại kỹ năng mềm}

Hiện nay, kỹ năng mềm là một trong những tiêu chí đánh giá nhân sự tuyển dụng mới, cũng đồng thời là tiêu chí đánh giá năng lực của người lao động trong quá trình làm việc. Từ lâu, việc trang bị kỹ năng mềm cho sinh viên đã trở thành một trong những tiêu chí hàng đầu của quá trình đào tạo nguồn nhân lực chất lượng cao. Ở các nước phát triển như Mỹ, Úc, Anh, Singapo,... kỹ năng mềm không chỉ được trang bị ở sinh viên mà ngay cả khi là học sinh tiểu học, kỹ năng mềm đã được chú trọng, đưa vào trau dồi hàng ngày và trở thành thói quen sinh hoạt của trẻ từ cấp tiểu học. Kỹ năng mềm luôn được kết hợp với kiến thức chuyên môn để phát huy tối đa hiệu quả công việc. Vì vậy, nguồn nhân lực ở các quốc gia này luôn được đánh giá cao. Tuy nhiên khi phân loại, mỗi quốc gia xây dựng những nhóm kỹ năng mềm quan trọng khác nhau nhằm đào tạo một thế hệ nhân sự có cả chuyên môn cao và kỹ năng mềm vững chắc.

Tại Mỹ: Bộ Lao động Mỹ (The U.S Department of Labor) cùng Hiệp hội Đào tạo và Phát triển Mỹ (The American Society of Training and Development) đã nghiên cứu về các kỹ năng cơ bản trong công việc và đưa ra nhóm 13 kỹ năng mềm gắn chặt với các kỹ năng lao động chuyên nghiệp như sau:

- Kỹ năng tự học (Learning to learn)

- Kỹ năng lắng nghe (Listening skills)

- Kỹ năng thuyết trình (Oral communication skills)

- Kỹ năng giải quyết vấn đề (Problem solving skills)

- Kỹ năng tư duy sáng tạo (Creative thinking skills)

- Kỹ năng quản lý bản thân và tinh thần tự tôn (Self esteem)

- Kỹ năng lập mục tiêu, động lực làm việc (Goal setting/Motivation skills)

- Kỹ năng định hướng phát triển sự nghiệp và con người (Personal and career development skills)

- Kỹ năng giao tiếp hiệu quả để tạo lập mối quan hệ (Interpersonal skills) 
- Kỹ năng phối hợp, làm việc cùng đồng đội (Teamwork)

- Kỹ năng đàm phán (Negotiation skills)

- Kỹ năng tổ chức, quản lý công việc hiệu quả (Organization effectiveness)

- Kỹ năng lãnh đạo (Leadership skills).

Tại Úc, Hội đồng Kinh doanh Úc (The Business Council of Australia - BCA) và Phòng thương mại và công nghiệp Úc (The Australian Chamber of Commerce and Industry - ACCI) đã xuất bản cuốn "Kỹ năng hành nghề cho tương lai" năm 2002. Cuốn sách cho thấy các kỹ năng và kiến thức mà người lao động yêu cầu bắt buộc phải có. Kỹ năng hành nghề (employability skills) là các kỹ năng cần để có việc làm và phát huy tối đa năng lực của bản thân, gồm 8 nhóm kỹ năng cụ thể sau:

- Kỹ năng giao tiếp (Communication skills)

- Kỹ năng làm việc nhóm hiệu quả (Teamwork skills)

- Kỹ năng giải quyết vấn đề (Problem solving skills)

- Kỹ năng sáng tạo và mạo hiểm (Initiative and enterprise skills)

- Kỹ năng lập kế hoạch và tiến hành công việc (Planning and organising skills)

- Kỹ năng quản lý bản thân (Self management skills)

- Kỹ năng học tập (Learning skills)

- Kỹ năng về công nghệ (Technology skills)

Tại Canada, Bộ Phát triển nguồn nhân lực và kỹ năng Canada cùng một số tổ chức phi lợi nhuận nghiên cứu và phân tích các xu hướng kinh tế, cũng như năng lực hoạt động của các tổ chức và các vấn đề chính sách công cộng có tên là Conference Board of Canada, đã đưa ra danh sách các kỹ năng hành nghề cho thế kỷ 21 (Employability Skills 2000+) gồm các kỹ năng như:

- Kỹ năng giao tiếp (Communication skills)

- Kỹ năng giải quyết vấn đề (Problem solving skills)

- Kỹ năng tư duy và hành vi tích cực (Positive attitudes and behaviours)

- Kỹ năng thích ứng (Adaptability)

- Kỹ năng làm việc với con người (Working with others)

- Kỹ năng nghiên cứu khoa học, công nghệ và toán (Science, technology and mathematics skills)

Không chỉ ở các nước phát triển mà hiện nay tất cả các nước tham gia vào quá trình hội nhập, trong đó có Việt Nam đều chú trọng vào việc định hướng và tìm ra giải pháp đào tạo nguồn nhân lực có kỹ năng cao. Đã có rất nhiều bài nghiên cứu về việc làm thế nào để nâng cao kỹ năng mềm cho học sinh, sinh viên đáp ứng xu thế toàn cầu hóa như hiện nay. Nhận thấy được tầm quan trọng của kỹ năng mềm đối với quá trình học tập và đáp ứng được yêu cầu của các nhà tuyển dụng, người sử dụng lao động, Trung tâm Đào tạo kỹ năng 
xã hội - Trường đại học Thủ Dầu Một đã sớm xây dựng chương trình đào tạo và liên tục lắng nghe ý kiến đóng góp từ phía doanh nghiệp, nhà tuyển dụng và từ nhu cầu của sinh viên để xây dựng nhóm các kỹ năng phù hợp, đáp ứng nhu cầu và kỳ vọng của sinh viên. Hiện tại, Trung tâm Đào tạo kỹ năng xã hội - Trường đại học Thủ Dầu Một đang đào tạo và bồi dưỡng các nhóm kỹ năng (Hình 1).

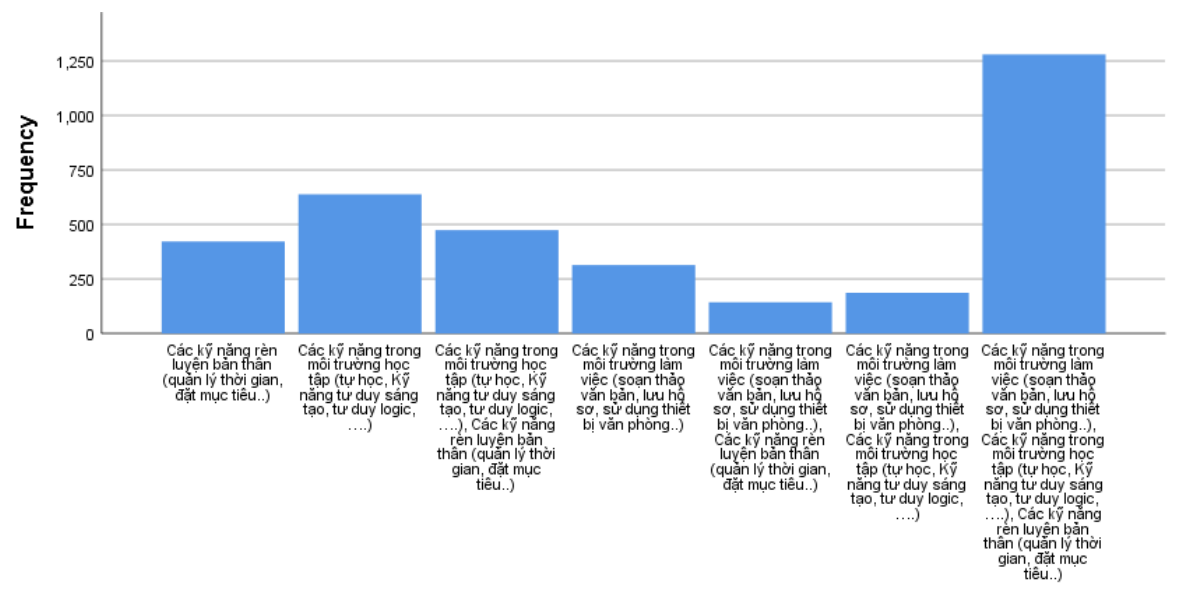

Hình 1. Các nhóm kỹ năng được sinh viên Đại học Thủ Dầu Một lựa chọn Nguồn: Tác giả tổng hợp tì̀ kết quả khảo sát của Trung tâm ĐTKNXH - TDMU

\subsection{Vai trò của Kỹ năng mềm và nhận thức của sinh viên Đại học Thủ Dầu Một về $\boldsymbol{k} \tilde{y}$ năng $\boldsymbol{m e \hat { e } m}$}

Nếu kỹ năng cứng sẽ giúp bạn có được công việc thì các kỹ năng mềm sẽ giúp bạn thành công và phát triển hơn. Kỹ năng mềm khác với kỹ năng cứng để chỉ trình độ chuyên môn, kiến thức chuyên môn hay bằng cấp và chứng chỉ chuyên môn. Thực tế cho thấy người thành đạt chỉ có $25 \%$ là do những kiến thức chuyên môn, $75 \%$ còn lại được quyết định bởi những kỹ năng mềm họ được trang bị. Tìm hiểu thêm về những kỹ năng mềm dễ mang lại cơ hội cho bạn.

\subsubsection{Vai trò của kỹ năng mềm đối với sinh viên}

- Vai trò của kỹ năng mềm trong quá trình học tập

Đối với sinh viên kỹ năng mềm rất quan trọng trong việc học tập hàng ngày, nhất là đối với sinh viên năm thứ nhất khi vừa mới thay đổi môi trường học tập. Mọi thứ với sinh viên là hoàn toàn mới, từ môi trường học tập, bạn bè, thầy cô, nội dung học tập và phương pháp dạy và học. Môi trường học đại học có tính "mở", đề cao vai trò chủ động, tự quyết định và chịu trách nhiệm của sinh viên. Hoạt động "học" và "hành" luôn đi liền với nhau nên việc vận dụng các kiến thức vào thực tế bằng kỹ năng mềm của mình mà cụ thể là kỹ năng học tập bậc đại học sẽ tạo ra hiệu quả cao và thích ứng nhanh hơn.

Gần đây, nhiều trường đại học ra quyết định buộc thôi học với hàng trăm, thậm chí là hàng ngàn sinh viên mỗi năm, trong đó có cả những sinh viên đạt điểm cao đầu vào. Điều đó cho thấy sự chủ quan, thích nghi chậm hoặc thiếu mục tiêu là một trong những lý do dẫn đến sự thất bại của sinh viên. Vì vậy được trang bị các kỹ năng kịp thời như Kỹ năng đặt 
mục tiêu, lập kế hoạch, quản lý thời gian; Kỹ năng khám phá và phát triển bản thân; Kỹ năng giải quyết vấn đề và ra quyết định... sẽ là công cụ hữu ích giúp sinh viên định hình công việc học tập của mình một cách có hiệu quả.

\section{- Vai trò của kỹ năng mềm trong quá trình tuyển dụng}

Trong quá trình tuyển dụng, nhiều sinh viên ra trường với tấm bằng tốt nhưng không thể đáp ứng được yêu cầu của nhà tuyển dụng vì thiếu các kỹ năng mềm. Khoảng $70 \%$ ra trường khó xin việc vì không có kinh nghiệm và thiếu các kỹ năng cần thiết. Cơ hội được làm việc ở những doanh nghiệp và tập đoàn lớn là điều không thể. Các nhà tuyển dụng thường đánh giá cao những nhân viên thể hiện được khả năng làm việc tốt trong tập thể. Hòa đồng với tập thể, không chỉ có tính cộng tác mà còn thể hiện được khả năng lãnh đạo tốt khi có thời điểm thích hợp. Một nhân viên thiếu kỹ năng giao tiếp, làm việc nhóm, kỹ năng thuyết trình, nói chuyện trước đám đông, kỹ năng lập kế hoạch, kỹ năng làm chủ bản thân... là điều khó có thể chấp nhận được. Điển hình trong một dự án đầu tư vào Việt Nam vào năm 2008, Intel đã tuyển hơn 2000 nhân sự, nhưng chỉ có 40 ứng viên đủ trình độ kiến thức lẫn kỹ năng mềm. Số còn lại, 1.960 người không dễ tuyển vì các ứng viên hầu như không nhận thức được thế mạnh bản thân, hoặc biết nhưng không thể hiện được khả năng nổi trội của mình và thường bối rối khi nói về bản thân.

\section{- Vai trò của kỹ năng mềm khi đi làm}

Hiện nay các nhà sử dụng lao động không chỉ yêu cầu người được tuyển dụng có trình độ chuyên môn mà còn đặt ra những tiêu chuẩn nhất định về kỹ năng và thái độ. Nếu như dựa vào kiến thức, để chọn đúng người, nhà tuyển dụng yêu cầu người dự tuyển phải có khả năng vận dụng kiến thức học được vào công việc thực tiễn, qua đó có thể phát huy tính sáng tạo, chủ động trong công việc, làm việc độc lập trong môi trường áp lực cao. Về phần kỹ năng mềm sẽ hỗ trợ chuyên môn của các ứng viên trong quá trình làm việc. Đây là phần yếu nhất của sinh viên vì thiếu sự rèn luyện. Hệ quả, đã có không ít sinh viên mới ra trường rất yếu ở kỹ năng giao tiếp, thuyết trình, làm việc đội nhóm, viết sai lỗi chính tả, không soạn thảo được một văn bản ở dạng đơn giản nhất. Điều này đã ảnh hưởng không nhỏ đến việc giữ chỗ làm, thăng tiến trong công việc. Nói cách khác, trong bất cứ ngành nghề nào thì đạo đức nghề nghiệp, thái độ với công việc, ý thức của bản thân là điều quan trọng nhất.

Trong các doanh nghiệp và đơn vị sử dụng lao động, việc người lao động có kiến thức chuyên môn, nhưng thiếu đi các kỹ năng mềm, đó sẽ là khoảng trống. Mỗi công việc, mỗi môi trường làm việc sẽ cần đến những nhóm kỹ năng khác nhau với mức độ khác nhau. Nhưng nhìn chung với tất cả các nhóm ngành nghề, kỹ năng đang ngày càng chiếm vị trí quan trọng trong lực lượng lao động. Chỉ đào tạo về chuyên môn là chưa đủ nếu không được trang bị các kỹ năng mềm, kỹ năng quan hệ con người, xây dựng đội nhóm... giúp người lao động giao tiếp, tương tác và hợp tác với nhau tốt hơn, từ đó mà hiệu quả công việc cũng được nâng cao.

\subsubsection{Nhận thức của sinh viên Đại học Thủ Dầu Một về kỹ năng mềm}

Để việc đào tạo và trang bị kỹ năng mềm cho sinh viên một cách có hiệu quả, thiết thực, không bị xem là hình thức, mang tính đối phó. Đòi hỏi cần phải có sự chuẩn bị đồng bộ, đồng thời cả 3 nhóm yếu tố cốt lõi: một là chương trình khung kỹ năng mềm bám sát 
các yêu cầu, tiêu chuẩn của nhà tuyển dụng; hai là nắm rõ nhận thức của sinh viên và mức độ quan tâm của sinh viên đối với các nhóm kỹ năng; và ba là cần tập hợp được đội ngũ giảng viên có kinh nghiệm và chuyên sâu về các nhóm kỹ năng để chia sẻ đến sinh viên. Nhận thức, tri thức và vốn sống của sinh viên về hoạt động rèn luyện kỹ năng mềm là cơ sở để hình thành, phát triển kỹ năng mềm.

Bảng 1. Mức độ hiểu biết của sinh viên Đại học Thủ Dầu Một về kỹ năng mềm

\begin{tabular}{|l|l|l|l|l|l|}
\hline \multicolumn{2}{|c|}{} & Tần suất & Phần trăm & $\begin{array}{l}\text { Giá trị } \\
\text { phần tram }\end{array}$ & $\begin{array}{l}\text { Phần trăm } \\
\text { tích lũy }\end{array}$ \\
\hline \multirow{3}{*}{ Giá trị } & Chưa biết & 996 & 28.8 & 28.8 & 28.8 \\
\cline { 2 - 6 } & Đã biết & 2461 & 71.2 & 71.2 & 100.0 \\
\cline { 2 - 7 } & Tổng & 3457 & 100.0 & 100.0 & \\
\hline
\end{tabular}

Nguồn: Tác giả tổng hợp tì̀ kết quả khảo sát của Trung tâm ĐTKNXH - TDMU

Năm học 2020-2021 trường Đại học Thủ Dầu Một có hơn 15.000 sinh viên, cùng hơn 1000 học viên, nghiên cứu sinh học tập và nghiên cứu ở 47 ngành đại học, 11 ngành cao học, 1 ngành tiến sĩ. Khi khảo sát ngẫu nhiên, rải đều ở tất cả các khóa và các ngành đào tạo, với 3457 phiếu trả lời khảo sát về sự hiểu biết đến kỹ năng mềm. Kết quả trả lời về việc đã biết về kỹ năng mềm chiếm tỉ lệ $71,2 \%$ số sinh viên được khảo sát (tương ứng 2461 sinh viên) (bảng 1).

Bảng 2. Mức độ ưng dụng kỹ năng mềm của sinh viên Đại học Thủ Dầu Một

\begin{tabular}{|l|l|c|c|c|c|}
\hline \multicolumn{2}{|c|}{} & Tần suất & Phần trăm & $\begin{array}{c}\text { Giá trị } \\
\text { phần trăm }\end{array}$ & $\begin{array}{c}\text { Phần trăm } \\
\text { tích lũy }\end{array}$ \\
\hline \multirow{3}{*}{ Giá trị } & $\begin{array}{l}\text { Đã hiểu nhưng chưa có sự ứng dụng } \\
\text { vào thực tế }\end{array}$ & 1530 & 44.3 & 44.3 & 44.3 \\
\cline { 2 - 6 } & $\begin{array}{l}\text { Đã hiểu và từng ứng dụng những kỹ } \\
\text { năng đó vào thực tế }\end{array}$ & 312 & 9.0 & 9.0 & 53.3 \\
\cline { 2 - 6 } & Chưa có cơ hội ứng dụng vào thực tế & 1615 & 46.7 & 46.7 & 100.0 \\
\cline { 2 - 6 } & Total & 3457 & 100.0 & 100.0 & \\
\hline
\end{tabular}

Nguồn: Tác giả tổng hợp tù̀ kết quả khảo sát của Trung tâm ĐTKNXH - TDMU

Qua quá trình khảo sát nhận thức của sinh viên về vai trò của kỹ năng mềm đối với việc học và đáp ứng yêu cầu của nhà tuyển dụng, có 3144 sinh viên tán thành về sự cần thiết của kỹ năng mềm (chiếm 90,9\% số sinh viên được khảo sát). Tuy nhiên trên thực tiễn qua các lớp học kỹ năng và các câu lạc bộ, sân chơi dành cho sinh viên rèn luyện kỹ năng, vẫn còn một số sinh viên chưa tích cực tham gia, hoặc tham gia ở mức độ đối phó. Nnhiều sinh viên chỉ tập trung vào việc làm sao để có một tấm bằng đẹp mà bỏ qua việc nâng cao các kỹ năng mềm. Sinh viên bỏ qua những chương trình hội thảo, những sân chơi bổ ích do Đoàn, Hội sinh viên tổ chức, các chương trình giáo dục kỹ năng mềm, những cơ hội thực tế để rèn luyện kỹ năng mềm.

Tâm lý chung của tất cả mọi người là không bao giờ làm những điều mà họ cho là không mang lại lợi ích cho mình vì nó sẽ lãng phí thời gian. Tâm lý đó cũng đúng với trường 
hợp của sinh viên lựa chọn các nhóm kỹ năng mềm. Tuy nhiên, việc trang bị kỹ năng gì không phải chỉ đơn thuần là sở thích hay lợi ích từ phía cá nhân, mà xét trên toàn diện sinh viên cần nắm bắt những yêu cầu về kỹ năng của nhóm ngành tương lai mình sẽ đảm nhận hoặc mong muốn được cống hiến, từ đó mà lựa chọn các kỹ năng cần thiết để bổ sung.

Bảng 3. Nhận thức của sinh viên Đại học Thủ Dầu Một về vai trò của kỹ năng mềm

\begin{tabular}{|l|l|l|l|l|l|}
\hline \multicolumn{2}{|l|}{} & Tần suất & Phần trăm & $\begin{array}{l}\text { Giá trị } \\
\text { phần trăm }\end{array}$ & $\begin{array}{l}\text { Phần trăm tích } \\
\text { lũy }\end{array}$ \\
\hline \multirow{3}{*}{ Giá trị } & $\begin{array}{l}\text { Cần thiết nhưng chưa phải yếu tố } \\
\text { quyết định }\end{array}$ & 313 & 9.1 & 9.1 & 9.1 \\
\cline { 2 - 6 } & Rất cần thiết & 3144 & 90.9 & 90.9 & 100.0 \\
\cline { 2 - 6 } & Total & 3457 & 100.0 & 100.0 & \\
\hline
\end{tabular}

Nguồn: Tác giả tổng hợp tù̀ kết quả khảo sát của Trung tâm ĐTKNXH - TDMU

Từ nhận thức chưa đúng và chưa đầy đủ về vai trò của kỹ năng mềm dẫn đến suy nghĩ rằng kỹ năng mềm không quan trọng, dẫn đến sự thiếu kiên nhẫn và quyết tâm hành động rèn luyện, trau dồi, tích lũy kỹ năng mềm, đã lấy đi nhiều cơ hội đáng kể đáng lẻ thuộc về các bạn, nhiều sinh viên sau khi tốt nghiệp vẫn loay hoay với bài toán đi tìm kiếm công việc sau những lần thất bại của tuyển dụng, mặc dù có nhiều bằng cấp.

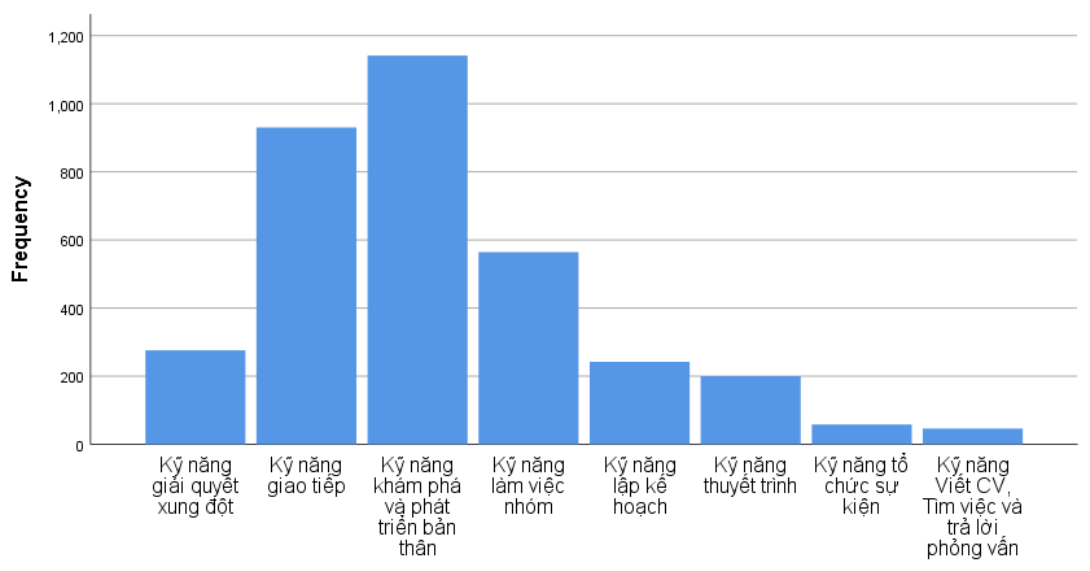

Hình 2. Một số kỹ năng sinh viên đã lựa chọn để rèn luyện

Nguồn: Tác giả tổng hợp tù kết quả khảo sát

Khảo sát đối với khoảng 3500 sinh viên các khóa của năm học 2017-2018, dựa vào mức độ lựa chọn cho thấy việc trang bị các kỹ năng của sinh viên có thể chia thành 3 nhóm: nhóm thứ nhất với tỷ lệ sinh viên tham gia cao, bao gồm kỹ năng khám phá và phát triển bản thân, kỹ năng giao tiếp và kỹ năng làm việc nhóm. Nhóm thứ hai, với tỷ lệ sinh viên tham gia ở mức trung bình, gồm các kỹ năng giải quyết xung đột, kỹ năng lập kế hoạch, kỹ năng thuyết trình. Nhóm thứ ba, có tỷ lệ sinh viên tham gia ở mức thấp, gồm kỹ năng tổ chức sự kiện và kỹ năng viết $\mathrm{CV}$, tìm việc và trả lời phỏng vấn.

Đánh giá về chất lượng của các khóa đào tạo kỹ năng mềm và các chương trình ngoại khóa hình thành và phát triển kỹ năng cũng là một trong những yếu tố tác động đến tâm lý và thái độ của sinh viên. Kết quả khảo sát cũng cho thấy, có tới $30,6 \%$ sinh viên đánh giá 
các khóa đào tạo kỹ năng mềm chỉ đạt được kỳ vọng ở mức bình thường và vẫn còn 5,6\% sinh viên cảm thấy chưa đáp ứng được yêu cầu của cá nhân. Điều này phản ánh một thực trạng đó là một số hoạt động rèn luyện kỹ năng vẫn chưa được thực hiện một cách có hiệu quả, và do đó chưa thu hút được nhiều sinh viên tham gia, hưởng ứng. Kết quả khảo sát cũng cho thấy sinh viên kỳ vọng vào cách thức tổ chức lớp học kỹ năng khá đa dạng, song tập trung vào yêu cầu lớp học có đội ngũ giảng viên có kinh nghiệm từ thực tế, ưu tiên các lớp học có xu hướng "mở” tạo tâm lý thoải mái và tăng cơ hội trải nghiệm khi rèn luyện kỹ năng (Hình 4).

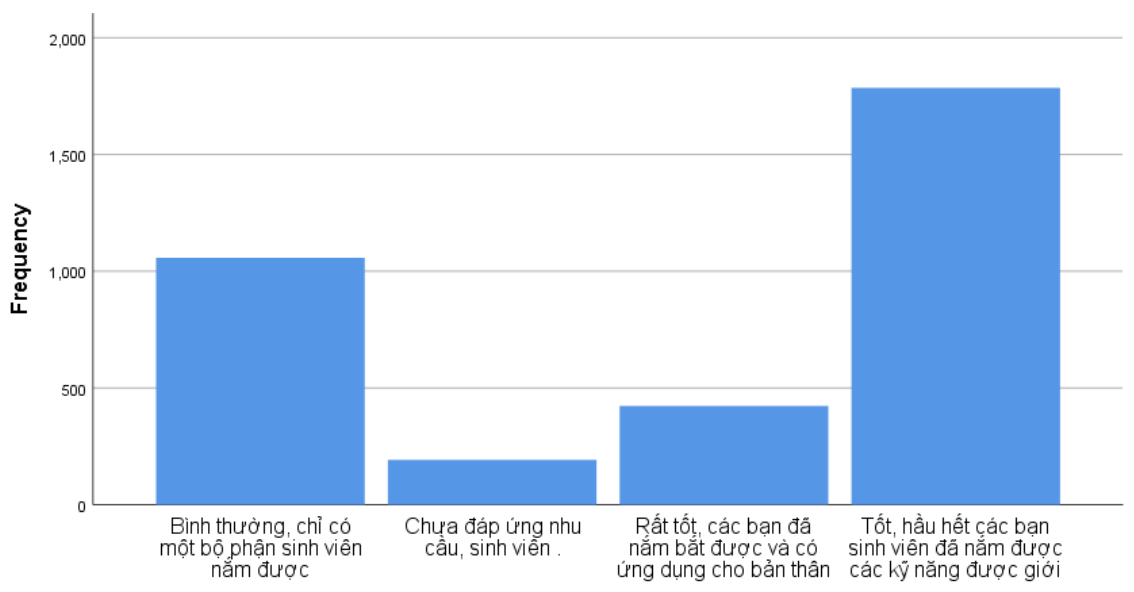

Hình 3. Mức độ đánh giá của sinh viên về hoạt động bồi duỡng kỹ năng tại truờng Nguồn: Tác giả tổng hợp tù̀ kết quả khảo sát

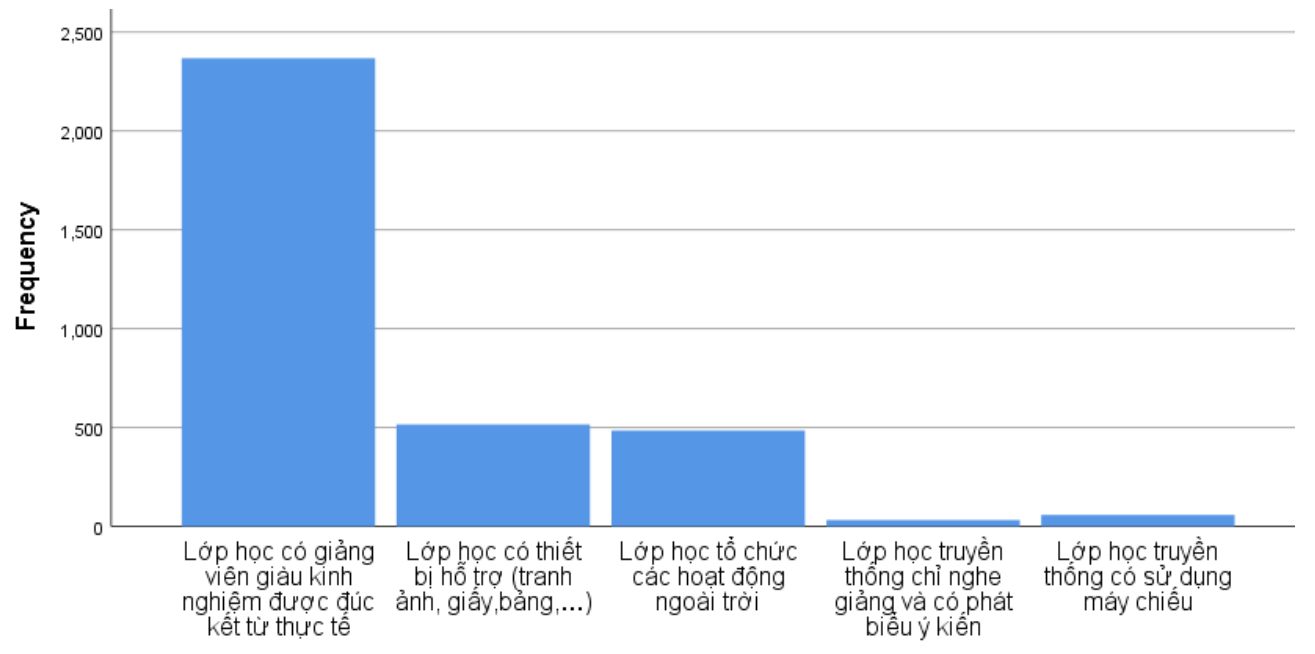

Hình 4. Hình thức tổ chức lớp học kỹ năng mềm sinh viên lựa chọn

Nguồn: Tác giả tổng hợp tùu kết quả khảo sát

Việc rèn luyện kỹ năng mềm cho sinh viên, về phía nhà trường chỉ đóng vai trò là chất xúc tác, ý thức chủ động và tự rèn luyện của mỗi sinh viên mới là yếu tố quyết định. Do đó, mỗi sinh viên cần phải có nhận thức chuẩn xác về tầm quan trọng của kỹ năng mềm, 
trang bị đầy đủ, kịp thời và thường xuyên vận dụng vào thực tiễn nhằm phát huy hiệu quả từ những kỹ năng đã được trang bị.

\subsection{Một số giải pháp phát triển kỹ năng mềm cho sinh viên Đại học Thủ Dầu Một đạt chuẩn đầu ra theo CDIO}

CDIO được viết tắt của cụm từ tiếng Anh Conceive - Design - Implement - Operate, có nghĩa là: hình thành ý tưởng, thiết kế ý tưởng, thực hiện và vận hành, khởi nguồn từ Viện Công nghệ MIT (Hoa Kỳ). CDIO là một đề xướng quốc tế lớn được hình thành để đáp ứng nhu cầu một thập kỷ mới của các doanh nghiệp và các bên liên quan khác trên toàn thế giới, trong việc nâng cao khả năng học tập trải nghiệm của sinh viên, đồng thời đẩy mạnh việc học các kỹ năng cá nhân và giao tiếp, kỹ năng kiến tạo sản phẩm...

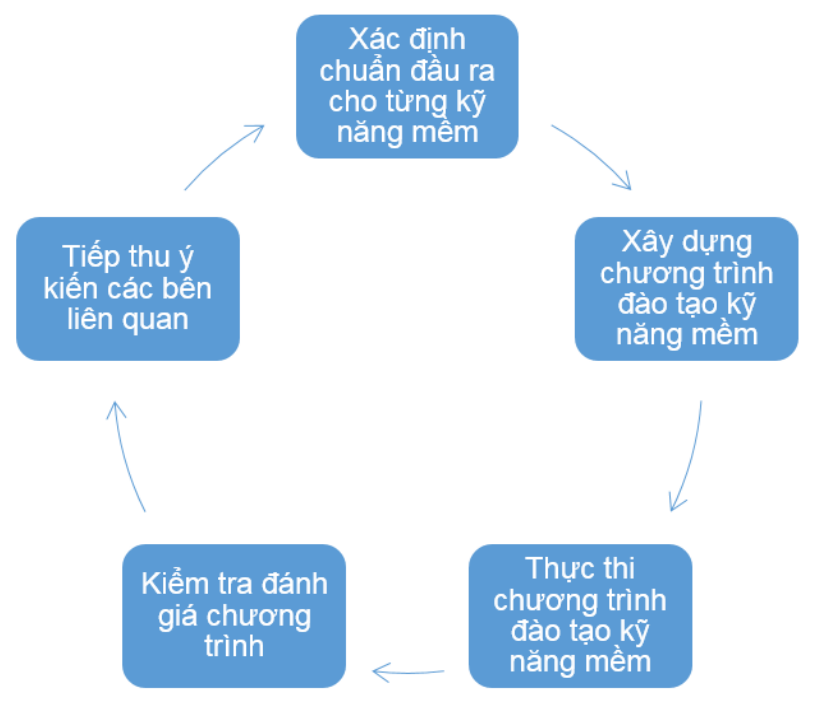

Hinh 5. So đồ phát triển kỹ năng mềm đạt chuẩn đầu ra theo CDIO

Chương trình đào tạo kỹ năng mềm được thiết kế theo chuẩn CDIO sẽ tập trung vào việc giải quyết các vấn đề: sinh viên cần làm những gì và làm như thế nào để đạt được kỹ năng mềm, đáp ứng yêu cầu của công việc và sự kỳ vọng của nhà tuyển dụng.

2.3.1. Tổ chức lấy ý kiến các bên liên quan (giảng viên, cựu sinh viên, nhà tuyển dụng, sử dụng lao động)

Khảo sát đối với các doanh nghiệp, người sử dụng lao động, cựu sinh viên đã ra trường và đi làm trong vai trò là người lao động, để nắm bắt được những yêu cầu và sự thay đổi của thị trường lao động đối với các kỹ năng mềm cần thiết, từ đó có những điều chỉnh, bổ sung kịp thời về chương trình đào tạo kỹ năng phù hợp với từng ngành và nhóm ngành. Phối hợp với các Khoa, các ngành đào tào tạo tổ chức các buổi tọa đàm, chia sẻ của nhà tuyển dụng để sinh viên nhận thức được tầm quan trọng của kỹ năng mềm đối với học tập, cuộc sống và đặc biệt là công việc sau này, thì sinh viên sẽ chủ động tìm đến và tự trang bị cho mình các kỹ năng.

Trung tâm Đào tạo kỹ năng xã hội phối hợp với Đoàn thanh niên, Hội sinh viên trường, các câu lạc bộ, đội nhóm... thường xuyên, định kỳ tổ chức các chương trình, sân chơi cho sinh viên. Thông qua sinh hoạt và thực tế giúp sinh viên có cơ hội vận hành và sử 
dụng, áp dụng các kỹ năng đã được trang bị hoặc nhận ra những kỹ năng còn thiếu, yếu để tiếp tục trao dồi, bồi dưỡng.

2.3.2. Tổng hợp ý kiến để chỉnh sửa chuẩn đầu ra kỹ năng mềm cho phù hợp. Xây dụng các nhóm kỹ năng mềm gợi ý cho tùng nhóm ngành và phù hợp với tùng giai đoạn đào tạo của sinh viên

Rà soát và điều chỉnh chuẩn đầu ra của từng kỹ năng, trên cơ sở của mục tiêu chương trình cũng như các yêu cầu đặc thù của ngành, bối cảnh xã hội và ý kiến góp ý của các bên liên quan. Hoàn thiện chuẩn đầu ra của từng kỹ năng, xây dựng thành nhóm kỹ năng theo nhu cầu của từng nhóm ngành để việc đào tạo đi vào chiều sâu và mang tính ứng dụng cao. Việc xây dựng chuẩn đầu ra cần hướng đến tiếp cận năng lực, chú trọng vào kết quả đầu ra (Outcomes) dựa theo thang đo Bloom, làm cơ sở cho việc xác định một cách rõ ràng những gì cần đạt được và đo lường (lượng hóa) các kết quả khi đánh giá..

Đồng thời bổ sung, lồng ghép kỹ năng mềm phù hợp với chuyên ngành đào tạo vào hoạt động đào tạo chuyên môn, lồng ghép thảo luận, làm việc nhóm, thuyết trình, thực hành trên lớp và ngay cả việc tự học của các bạn sinh viên. Sự nhấn mạnh và đánh giá nghiêm túc, khách quan của thầy cô về mức độ tham gia, vận dụng thành thạo các kỹ năng mềm để sinh viên nhận thấy được tầm quan trọng của kỹ năng, từ đó tự giác rèn luyện thông qua phương pháp học tập mỗi môn học.

\subsubsection{Nâng cao năng lục của đội ngũ giảng viên tham gia đào tạo kỹ năng}

Tập hợp đội ngũ cán bộ giảng viên, chuyên gia am tường về kiến thức và có nhiều kinh nghiệm tham gia vào việc giảng dạy, chia sẻ kỹ năng đến sinh viên. Điều này là thực sự cần thiết trong bối cảnh hiện nay, khi phần lớn các nhà tuyển dụng thông qua phỏng vấn, tuyển dụng và sử dụng sinh viên tốt nghiệp sẽ có cái nhìn đánh giá về chất lượng và uy tín của trường. Do đó, chỉ khi năng lực và kinh nghiệm của giảng viên được nâng cao thì khả năng về kỹ năng mềm của sinh viên mới nhờ đó mà được cải thiện.

Bên cạnh đó, cần tổ chức các buổi báo cáo chuyên đề về kỹ năng giữa các nhóm giảng viên giảng dạy kỹ năng, hoặc mời các chuyên gia để tập huấn nhằm giao lưu và chia sẻ kinh nghiệm thực tế, tìm ra phương cách truyền đạt và tiếp nhận, vận hành tối ưu nhất đối với người học.

2.3.4. Đa dạng hóa các hình thức - phwơng pháp giảng dạy kỹ năng, tạo hưng thú cho sinh viên trong quá trình tiếp cận và vận dụng

Tùy vào đặc thù về mục tiêu và chuẩn đầu ra của từng kỹ năng để có thể linh hoạt lựa chọn các cách thức, phương pháp giảng dạy. Bên cạnh các phương pháp truyền thống đã và đang thực hiện, có thể đa dạng hóa việc rèn luyện kỹ năng thông qua các hội thảo chuyên đề, semina, các câu lạc bộ, hoạt động phong trào đoàn, hoạt động thiện nguyện, các hoạt động gắn với thực tiễn xã hội, tham gia các cuộc thi, dự án... với nội dung và hình thức mới mẻ, hấp dẫn. Các hoạt động này nên được tổ chức thường xuyên và tạo cơ hội bình đẳng cho tất cả sinh viên tham gia, tránh việc chỉ tập trung vào một số sinh viên nổi trội.

\subsubsection{Nâng cao ý thức, chủ động rèn luyện kỹ năng mềm của sinh viên}


Về phía sinh viên, trước hết cần nhận thức đúng đắn về vai trò, tầm quan trọng của kỹ năng mềm trong việc thích ứng môi trường học tập mới và phục vụ nghề nghiệp sau này. Bản thân sinh viên trước hết phải xác định rõ công việc mình muốn làm sau khi ra trường, từ đó phân tích để nhận ra với công việc đó, đâu sẽ là kỹ năng "cứng”, đâu sẽ là kỹ năng "mềm". Việc xác định rõ "cứng", "mềm" và nhận ra điểm mạnh, điểm yếu, những mặt thiếu hụt của bản thân là yêu cầu đầu tiên và rất quan trọng. Đồng thời, sinh viên cũng cần năng động và chủ động, tích cực tham gia các hoạt động do nhà trường tổ chức để tận dụng cơ hội rèn luyện. Chỉ khi tham gia các hoạt động ngoại khóa sinh viên mới có nhiều cơ hội để đánh giá chính xác, khách quan mức độ và năng lực về kỹ năng vốn có của bản thân.

\section{Kết luận}

Bài viết đã làm rõ thực trạng về nhận thức của sinh viên Đại học Thủ Dầu Một đối với vai trò của kỹ năng mềm, qua kết quả khảo sát và từ thực tế hoạt động đào tạo kỹ năng mềm của Trung tâm Đào tạo kỹ năng xã hội cho thấy nhà trường đã có sự quan tâm trong việc xây dựng chương trình, kế hoạch đào tạo, rèn luyện kỹ năng cho sinh viên. Bổ sung và cập nhật kịp thời các kỹ năng trên cơ sở lắng nghe ý kiến góp ý từ phía các đơn vị tuyển dụng, sử dụng lao động và từ bối cảnh, nhu cầu xã hội.

Tuy nhiên, để nâng cao hơn nữa chất lượng đào tạo các khóa kỹ năng, vừa thỏa mãn sự mong đợi của sinh viên, đồng thời đáp ứng các yêu cầu về năng lực làm việc của nhà tuyển dụng, cần tiếp tục cải tiến và hoàn thiện chương trình đào tạo kỹ năng mềm đáp ứng chuẩn đầu ra theo CDIO như những giải pháp tác giả đã đề xuất để trường Đại học Thủ Dầu Một trở thành địa chỉ uy tín trong đào tạo, sinh viên trở thành người phát triển toàn diện về năng lực và tố chất, nhằm phục vụ cộng đồng.

\section{Tài liệu tham khảo}

[1] Trung tâm CEE - Đại học Khoa Học Tự Nhiên - Đại học Quốc Gia TP.HCM, "Tài liệu hỗ trợ đợt tập huấn CDIO tháng 8/2014 Đại học Thủ Dầu Một”, TP. HCM, 2014.

[2] Đại học Quốc gia thành phố Hồ Chí Minh (2012), "Đào tạo đáp ứng nhu cầu xã hội và hội nhập quốc tế", Hội nghị CDIO toàn quốc.

[3] Đoàn Thị Minh Trinh, Nguyễn Hội Nghĩa, "Hướng dẫn thiết kế và phát triển Chương trình đào tạo đáp ứng chuẩn đầu ra”, NXB, Đại học Quốc Gia TPHCM, 2014.

[4] Hồ Tấn Nhựt, Đoàn Thị Minh Trinh, "Cải cách và xây dựng chương trình đào tạo kỹ thuật theo phương pháp tiếp cận CDIO”, NXB, Đại học Quốc Gia TPHCM, 2010. 